\title{
Sleep hypoventilation in hypercapnic chronic obstructive pulmonary disease: prevalence and associated factors
}

\author{
F.J. O'Donoghue*,\#, P.G. Catcheside*, E.E. Ellis ${ }^{\Uparrow}$, R.R. Grunstein ${ }^{+}$, R.J. Pierce ${ }^{\S}$, \\ L.S. Rowland*, E.R. Collins ${ }^{+}$, S.E. Rochford ${ }^{\S}$, R.D. McEvoy*\#, \\ for the Australian trial of Noninvasive Ventilation in Chronic Airflow Limitation (AVCAL) investigators
}

Sleep hypoventilation in hypercapnic chronic obstructive pulmonary disease: prevalence and associated factors. F.J. O' Donoghue, P.G. Catcheside, E.E. Ellis, R.R. Grunstein, R.J. Pierce, L.S. Rowland, E.R. Collins, S.E. Rochford, R.D. McEvoy, for the Australian trial of Noninvasive Ventilation in Chronic Airflow Limitation (AVCAL) investigators. (C) ERS Journals Ltd 2003.

ABSTRACT: Sleep hypoventilation (SH) may be important in the development of hypercapnic respiratory failure in chronic obstructive pulmonary disease (COPD). The prevalence of $\mathrm{SH}$, associated factors, and overnight changes in waking arterial blood gases (ABG), were assessed in 54 stable hypercapnic COPD patients without concomitant sleep apnoea or morbid obesity.

Lung function assessment, anthropomorphic measurements, and polysomnography with ABG measurement before and after sleep were conducted in all patients. Transcutaneous carbon dioxide tension $\left(\mathrm{P}_{\mathrm{t}}, \mathrm{CO}_{2}\right)$ was measured in sleep, using simultaneous arterial carbon dioxide tension $\left(\mathrm{Pa}_{\mathrm{a}}, \mathrm{CO}_{2}\right)$ for in vivo calibration and to correct for drift in the sensor.

Of the patients, $43 \%$ spent $\geqslant 20 \%$ of sleep time with $P \mathrm{t}, \mathrm{CO}_{2}>1.33 \mathrm{kPa}(10 \mathrm{mmHg})$ above waking baseline. Severity of $\mathrm{SH}$ was best predicted by a combination of baseline $\mathrm{Pa}_{\mathrm{a}} \mathrm{CO}_{2}$, body mass index and per cent rapid-eye movement (REM) sleep. REM-related hypoventilation correlated significantly with severity of inspiratory flow limitation in REM, and with apnoea/hypopnoea index. $\mathrm{Pa}_{\mathrm{a}} \mathrm{CO}_{2}$ increased mean $\pm \mathrm{SD} 0.70 \pm 0.65 \mathrm{kPa}$ $(5.29 \pm 4.92 \mathrm{mmHg})$ from night to morning, and this change was highly significant. The change in $\mathrm{Pa}_{\mathrm{a}}, \mathrm{CO}_{2}$ was strongly correlated with severity of $\mathrm{SH}$.

Sleep hypoventilation is common in hypercapnic chronic obstructive pulmonary disease, and related to baseline arterial carbon dioxide tension, body mass index and indices of upper airway obstruction. Sleep hypoventilation is associated with significant increases in arterial carbon dioxide tension night-to-morning, and may contribute to long-term elevations in arterial carbon dioxide tension.

Eur Respir J 2003; 21: 977-984.
*Adelaide Institute for Sleep Health, Repatriation General Hospital, Daw Park, South Australia, ${ }^{\#}$ Faculty of Medicine, Flinders University of South Australia, South Australia, Faculty of Health Sciences, University of Sydney, New South Wales, ${ }^{+}$Centre for Respiratory Failure and Sleep Disorders and Institute of Respiratory Medicine, Royal Prince Alfred Hospital, Camperdown, New South Wales, and ${ }^{\$}$ Institute for Breathing and Sleep, Austin and Repatriation Medical Centre, Heidelberg, Victoria, Australia.

Correspondence: F.J. O'Donoghue, Institute for Breathing and Sleep, Austin and Repatriation Medical Centre, Heidelberg, Victoria, Australia.

Fax: 61394965124

E-mail: fods66@iprimus.com.au

Keywords: Chronic obstructive pulmonary disease

hypercapnia

sleep hypoventilation

Received: July 242002

Accepted after revision: January 152003

This study was funded by grants from the Australian National Health and Medical Research Council and Air Liquide Australia.
Chronic obstructive pulmonary disease (COPD) is a major cause of morbidity and is now the fourth-leading cause of death in the USA [1]. Chronic hypercapnia is known to be a poor prognostic factor in COPD [2] but the causes of hypercapnia are not completely understood [3]. Patients with severe COPD are known to be at risk of sleep hypoventilation (SH) [4] and it has been proposed that $\mathrm{SH}$ may play a role in the pathogenesis of chronic hypercapnia through blunting of central chemoreceptor responses to carbon dioxide $\left(\mathrm{CO}_{2}\right)$, secondary to gradual renal $\mathrm{HCO}_{3}{ }^{-}$ retention $[3,5]$. In support of this hypothesis are the results from a trial of nocturnal noninvasive ventilation (NIV) in COPD, which showed improvements in awake arterial carbon dioxide tension $\left(\mathrm{Pa}, \mathrm{CO}_{2}\right)$ [6]. $\mathrm{Pa}, \mathrm{CO}_{2}$ correlated solely with reductions in transcutaneous carbon dioxide tension $\left(P \mathrm{t}, \mathrm{CO}_{2}\right)$ during sleep.

Despite its potential importance for prognosis, no study has investigated the prevalence of $\mathrm{SH}$ in hypercapnic COPD. However, it is known that transient oxygen desaturation is common in severe COPD [7], and particularly in hypercapnic COPD [8]. This phenomenon is at least partly due to hypoventilation, but there may also be a contribution from altered ventilation/perfusion $\left(V^{\prime} / Q^{\prime}\right)$ relationships [7, 9]. The mechanisms of SH in hypercapnic COPD are also uncertain. A fall in central respiratory drive, particularly in rapid-eye movement (REM) sleep, is likely to be important [7] but there may also be a significant contribution from increased upper airways resistance. "Overlap syndrome", the combination of COPD and obstructive sleep apnoea/hypopnoea syndrome $(\mathrm{OSAH})$, is said to predispose to daytime hypercapnia and hypoxaemia independently of lung function [10]. However, the role of the upper airway in SH in COPD patients without overt OSAH has received little attention. An increase in upper airways resistance at sleep onset may contribute to the fall in ventilation during sleep in normal subjects [11]. It is therefore possible that patients whose respiratory muscles are working close to their endurance limits [12] cannot compensate for the extra load imposed by the upper airway during sleep.

The present study was conducted in order to address some of these questions. To do this the baseline data for the first 80 patients enrolled in the Australian trial of Noninvasive Ventilation in Chronic Airflow Limitation (AVCAL) was analysed. AVCAL is a multicentre, randomised, controlled trial of chronic domiciliary NIV in stable hypercapnic COPD. 
Recruitment commenced in 1998. There were three main aims of the present study: 1) to document the prevalence of $\mathrm{SH}$ in stable hypercapnic COPD; 2) to determine which factors are associated with $\mathrm{SH}$ in this population with the specific hypothesis that factors linked with increased upper airways resistance during sleep (obesity, alcohol consumption, snoring and inspiratory flow limitation in sleep) would worsen hypoventilation; and 3) to determine if awake $P \mathrm{a}, \mathrm{CO}_{2}$ is higher in the morning than in the evening in these subjects, and if the night-to-morning change in $\mathrm{Pa}, \mathrm{CO}_{2}$ correlates with severity of $\mathrm{SH}$.

\section{Materials and methods}

\section{Patients}

All patients were undergoing baseline assessment in Adelaide, Melbourne or Sydney, Australia, for the AVCAL trial. All respiratory physicians in these three centres were contacted directly to inform them of the trial aims and design. They were provided with inclusion and exclusion criteria and requested to refer all patients they considered appropriate for assessment. Advertisements were also placed in newsletters of the Royal Australasian College of Physicians, the Thoracic Society of Australia and New Zealand and the Australasian Sleep Association.

The inclusion criteria were: 1) a clinical history consistent with stable COPD without an exacerbation of airways disease for at least 4 weeks at the time of evaluation; 2) irreversible airflow obstruction (forced expiratory volume in one second (FEV1) $<1.5 \mathrm{~L}$ or $<50 \%$ predicted, FEV1/forced vital capacity $<65 \%, \Delta$ FEV1 with bronchodilator $<15 \%$, or if FEV1 $<1.5 \mathrm{~L}$, $\triangle$ FEV1 $<200 \mathrm{~mL}$ ); 3) daytime awake $P$ a, $\mathrm{CO}_{2}>6.12 \mathrm{kPa}$ $(46 \mathrm{mmHg})$ while in a stable condition; and 4) on oxygen therapy for a minimum of 3 months with a prescription meeting American Thoracic Society guidelines.

The exclusion criteria were: 1) morbid obesity (body mass index $(\mathrm{BMI}) \geqslant 40)$; 2) significant OSAH (apnoea/hypopnoea index $(\mathrm{AHI}) \geqslant 20 \cdot \mathrm{h}^{-1}$ (see scoring criteria below)); 3 ) previous treatment with domiciliary NIV; and 4 ) age $\geqslant 80$ yrs.

The protocol was approved by the Research and Ethics Committees of all participating institutions. All participants gave informed written consent.

\section{Measurements}

Height and weight were measured and BMI calculated. Spirometry pre- and postbronchodilator, lung volumes and single-breath diffusion capacity of the lung for carbon monoxide were recorded. Arterial blood was drawn for blood-gas analysis while on the prescribed flow of oxygen, and after breathing room air for $15 \mathrm{~min}$, if tolerated.

Full-attended polysomnography was performed (Compumedics S series, Abbotsford, Victoria, Australia) while on prescribed oxygen flow delivered by nasal cannulae. Measured parameters were electroencephalography (EEG), left and right electro-oculography, submental electromyography, airflow (by thermistor and/or by nasal pressure cannula), thoracoabdominal movement by inductance bands, leg movements, body position, and arterial oxygen saturation.

$P \mathrm{t}, \mathrm{CO}_{2}$ was recorded in all subjects with the TINA TCM 3 device (Radiometer, Copenhagen, Denmark) calibrated according to the manufacturers instructions. Arterial blood gases (ABG) were measured in the evening prior to sleep and again in the morning at least $5 \mathrm{~min}$ after final awakening, on an identical flow of oxygen while supine. Wakefulness was confirmed on the EEG. The simultaneous stable $P$ t, $\mathrm{CO}_{2}$ value at the time of each blood gas sample was noted.

A detailed history of lifetime alcohol consumption was taken using the "timeline followback" technique [13]. This involves aiding patients' memories of their past alcohol intake by using key events in their lives, e.g. first job, armed forces service, marriage, divorce, retirement, death of spouse etc. The technique has been validated previously and gives highly reproducible results $[13,14]$. The information was used to calculate lifetime alcohol consumption and current consumption.

\section{Data processing}

Sleep was manually staged in 30 -s epochs according to standard criteria [15]. Apnoea was defined as a complete cessation of airflow for $10 \mathrm{~s}$. Hypopnoea was defined as a $>50 \%$ reduction in amplitude in two of the following for $>10$ s: airflow, thoracic and abdominal respiband signals. Because all patients were on supplemental oxygen, no desaturation criterion was used in scoring hypopnoeas. For this reason, a rather high AHI cut-off $\left(\geqslant 20 \cdot \mathrm{h}^{-1}\right)$ was used in eliminating subjects with OSAH. In the Sleep Heart Health Study cohort, it was found that omitting desaturation from the criteria for scoring respiratory events produced up to a 10 -fold increase in median AHI [16].

Night-to-morning $\triangle P \mathrm{a}, \mathrm{CO}_{2}$ were calculated. $P \mathrm{t}, \mathrm{CO}_{2}$ data were sampled at $1 \mathrm{~Hz}$ and mean $P \mathrm{t}, \mathrm{CO}_{2}$ values calculated for each epoch of sleep. Evening $\mathrm{Pa}_{\mathrm{a}} \mathrm{CO}_{2}$ was used as an in vivo calibration (fig. 1) to adjust for baseline offset in $\mathrm{Pt}, \mathrm{CO}_{2}$ measurements.

Simultaneous $P \mathrm{t}, \mathrm{CO}_{2}$ and $\mathrm{Pa}, \mathrm{CO}_{2}$ results were examined before and after sleep. If the $P \mathrm{t}, \mathrm{CO}_{2}$ minus $P \mathrm{a}, \mathrm{CO}_{2}$ had changed across the night, this change was attributed to $P \mathrm{t}, \mathrm{CO}_{2}$ sensor drift. The morning $P \mathrm{t}, \mathrm{CO}_{2}$ value was corrected for this drift, and all $P \mathrm{t}, \mathrm{CO}_{2}$ values in between were corrected using linear interpolation (fig. 1).

SH was defined as $>20 \%$ of total sleep time (TST) spent with "corrected" $\mathrm{Pt}, \mathrm{CO}_{2}>1.33 \mathrm{kPa}(10 \mathrm{mmHg})$ above supine waking baseline levels. Severity of $\mathrm{SH}$ was assessed in each subject in three ways: 1) the increment in $\mathrm{Pt}_{\mathrm{t}} \mathrm{CO}_{2}$ (wakefulnesssleep) above which $20 \%$ of TST was spent (20\%incr; fig. 2 ); 2) the maximal increment of $\mathrm{Pt}_{1} \mathrm{CO}_{2}$ (maxincr; fig. 2); and 3) REM-related hypoventilation, measured as the mean rise in $P \mathrm{t}, \mathrm{CO}_{2}$ from the average in the preceding $5 \mathrm{~min}$ of nonrapid-eye movement (NREM) sleep to the maximum in each period of REM ( $\triangle$ NREM-REM). This value is less likely to be influenced by drift in the $P$ t, $\mathrm{CO}_{2}$ sensor as the change is calculated over a much shorter time period, usually $<15$ min.

If a drift of $<1.33 \mathrm{kPa}(10 \mathrm{mmHg}$ ) was seen from night-tomorning in the $P \mathrm{t}, \mathrm{CO}_{2}$ sensor, or if evening and morning $P \mathrm{a}, \mathrm{CO}_{2}$ were not available to validate $P \mathrm{t}, \mathrm{CO}_{2}$, the $20 \%$ incr and the maxincr values were excluded from analysis but the $\triangle$ NREM-REM values were retained.

Stable sleep was defined as an epoch without a stage change in the previous four epochs. A random sample of 10 nonconsecutive epochs of stable sleep in each stage was chosen by computer in each of the 54 patients in whom nasal pressure was measured. Each breath was visually scored for the presence of inspiratory flow limitation, without reference to the $\mathrm{SH}$ or blood-gas data for that subject, by a physician experienced in evaluation of inspiratory flow limitation from clinical data. Breaths were scaled to be of approximately uniform duration and amplitude. Evaluation was made purely on the basis of the shape of the inspiratory nasal pressure trace [17]. Breaths were assigned a score of 0,1 or 2 corresponding to no flow limitation, mildly flow-limited, or 


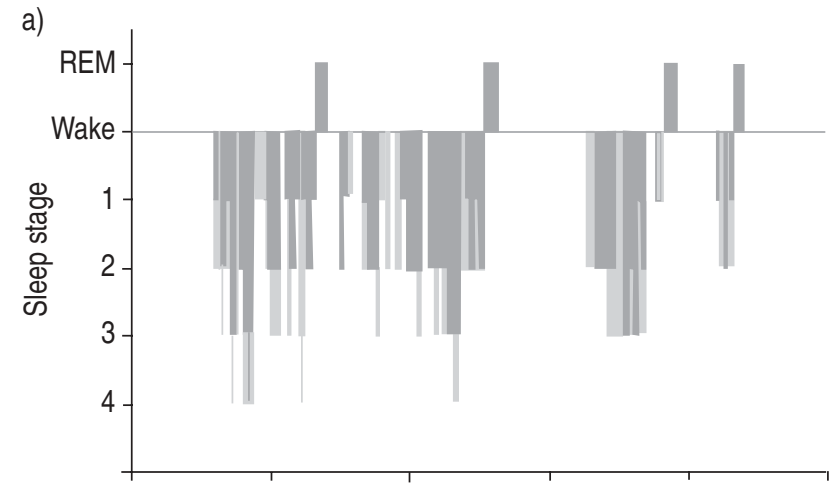

b)

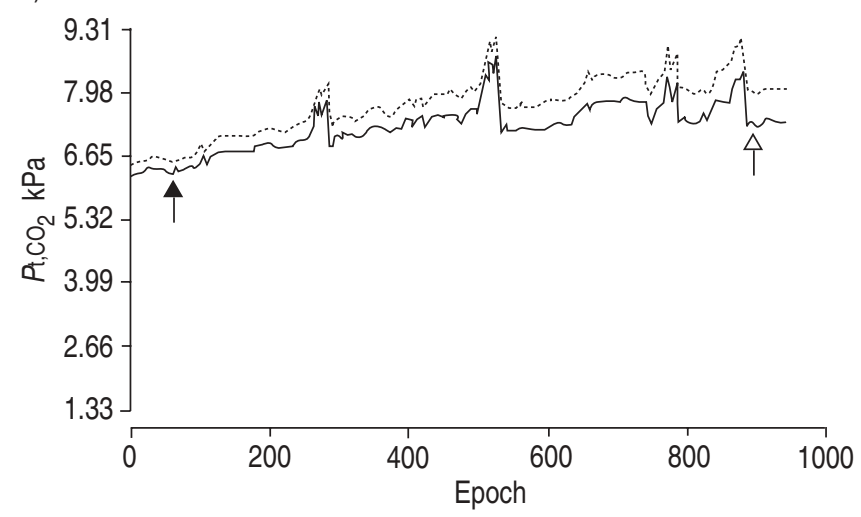

Fig. 1.-a) Sample hypnogram and b) transcutaneous carbon dioxide tension $\left(\mathrm{Pt}_{\mathrm{t}, \mathrm{CO}_{2}}\right)$ record illustrating $P \mathrm{t}, \mathrm{CO}_{2}$ corrections. The evening arterial carbon dioxide tension $\left(P \mathrm{a}, \mathrm{CO}_{2}\right)$ sample was used as an in vivo calibration and the morning $P \mathrm{a}_{\mathrm{a}} \mathrm{CO}_{2}$ to correct for $P \mathrm{t}, \mathrm{CO}_{2}$ sensor drift. Closed arrow indicates epoch $55\left(P \mathrm{t}, \mathrm{CO}_{2} 6.61 \mathrm{kPa}(49.7 \mathrm{mmHg}), P \mathrm{a}, \mathrm{CO}_{2}\right.$ $6.29 \mathrm{kPa}(47.3 \mathrm{mmHg}))$; Open arrow indicates epoch $923\left(\mathrm{Pt}_{\mathrm{t}, \mathrm{CO}_{2}}\right.$ $\left.8.09 \mathrm{kPa}(60.8 \mathrm{mmHg}), P_{\mathrm{a}, \mathrm{CO}_{2}} 7.39 \mathrm{kPa}(55.6 \mathrm{mmHg})\right)$. REM: rapideye movement. —: corrected $\mathrm{Pt}_{\mathrm{t}} \mathrm{CO}_{2} ; \cdots \cdots \cdots$. uncorrected $\mathrm{P}_{\mathrm{t}, \mathrm{CO}_{2}}$.

markedly flow-limited. A mean score per breath was derived for each stage of NREM sleep. These were then weighted according to the percentage of total NREM sleep occupied by

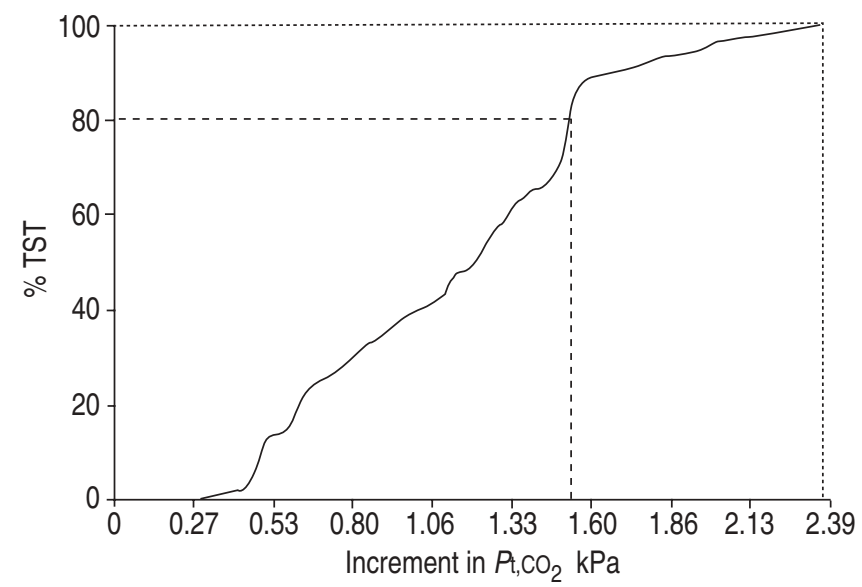

Fig. 2.-Cumulative frequency of transcutaneous carbon dioxide tension $\left(P_{\left.\mathrm{t}, \mathrm{CO}_{2}\right)}\right.$ values expressed as the increment in $P_{\mathrm{t}, \mathrm{CO}_{2}}$ over waking baseline, with time expressed as percentage total sleep time

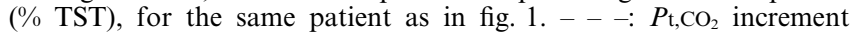
above which $20 \%$ of TST was spent $(1.53 \mathrm{kPa}(11.5 \mathrm{mmHg})) ; \cdots \cdots \cdots \cdots$ : maximum increment in $\mathrm{Pt}_{\mathrm{t}, \mathrm{CO}_{2}}(2.37 \mathrm{kPa}(17.84 \mathrm{mmHg}))$. that stage, and a weighted mean for all of NREM sleep was calculated. A separate mean score per breath was calculated for REM (REMflow). A blind rescoring in a random sample of 65 epochs produced a concordance of $87 \%$.

\section{Statistics}

The correlations between lung function and blood-gas parameters, as well as reported alcohol consumption, indices of inspiratory flow limitation and polysomnographic variables with measures of SH were assessed using Pearson's product moment with Spearman's rho for non-normally distributed variables. Predictive power of combinations of variables was assessed using forward stepwise-linear regression, with criteria for entry into the model being a probability of $\mathrm{F}$ of $<0.05$ and for removal a probability of $>0.1$. Comparison of evening and morning ABG measurements was performed using paired t-tests. Results are given as mean \pm SD unless otherwise stated.

\section{Results}

Baseline data from the first 80 patients (54 male, 26 female) enrolled in the AVCAL trial were analysed. Evening and morning blood-gas samples were taken from 67 patients under satisfactory conditions as defined above. There was no systematic overestimation of $\Delta P \mathrm{a}, \mathrm{CO}_{2}$ by $P \mathrm{t}, \mathrm{CO}_{2}$ as $\Delta \mathrm{Pa}, \mathrm{CO}_{2}$ increased (fig. 3).

Amongst these 67, data on $\mathrm{Pt}_{1} \mathrm{CO}_{2}$ trends across the night were excluded from analysis in 13 because of excessive drift of the $P \mathrm{t}, \mathrm{CO}_{2}$ sensor (11 patients), very high $P \mathrm{t}, \mathrm{CO}_{2}$ values that were outside the range of the recording equipment (one patient) and failure to record $P \mathrm{t}, \mathrm{CO}_{2}$ value at the time of $\mathrm{ABG}$ (one patient). Data on overnight trends in $\mathrm{Pt}, \mathrm{CO}_{2}$ were analysed in the remaining 54 patients. Their ages, baseline lung function and $\mathrm{ABG}, \mathrm{BMI}$ and polysomnographic variables are shown in table 1. There was no significant difference in any of the parameters in table 1 between the excluded patients and those in whom SH data was retained. In these 54 subjects the mean

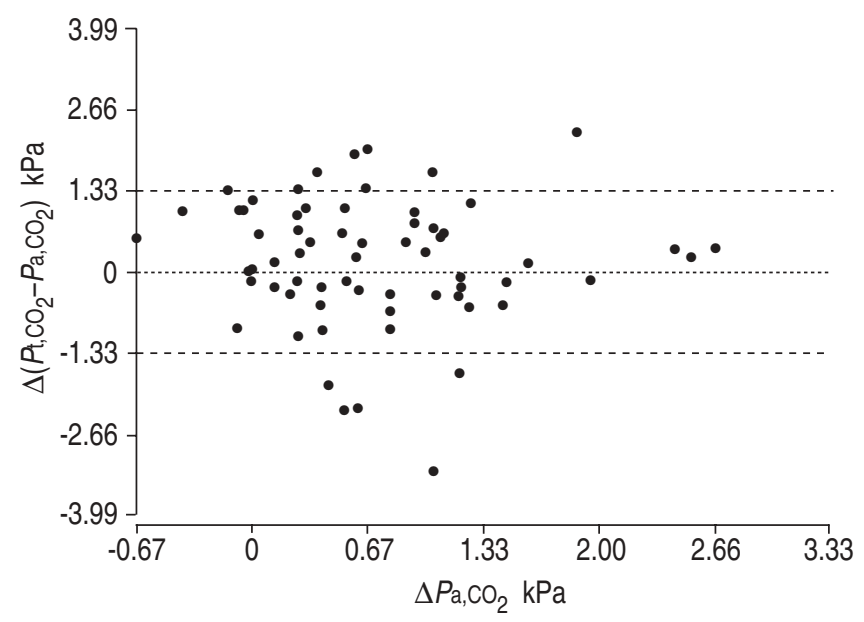

Fig. 3.-Error in measurement of change in arterial carbon dioxide tension $\left(\mathrm{Pa}_{\mathrm{a}} \mathrm{CO}_{2}\right)$ night-to-morning by transcutaneous carbon dioxide tension $\left(P \mathrm{t}, \mathrm{CO}_{2}\right)$. There was no relationship between $\left(P \mathrm{t}, \mathrm{CO}_{2}-P_{\mathrm{a}}, \mathrm{CO}_{2}\right)$ and $\Delta P \mathrm{a}_{1} \mathrm{CO}_{2}$, indicating there was no systematic overestimation of changes in $P \mathrm{a}, \mathrm{CO}_{2}$ by $P \mathrm{t}, \mathrm{CO}_{2}$. Therefore, changes in $\left(P \mathrm{t}, \mathrm{CO}_{2}-P_{\mathrm{a}}, \mathrm{CO}_{2}\right)$ were assumed to be due to drift in the $P_{t}, \mathrm{CO}_{2}$ sensor. Data from subjects in whom $P_{\mathrm{t}, \mathrm{CO}_{2}}$ measurements demonstrated drift of $>1.33 \mathrm{kPa}(10 \mathrm{mmHg})$ were excluded from analysis. In the remaining 54 subjects, drift in the $\mathrm{P}_{\mathrm{t}, \mathrm{CO}_{2}}$ sensor was corrected for, as in figure 1 . 
Table 1.-Baseline characteristics

Characteristics

Subjects $n$

Age yrs

BMI $\mathrm{kg} \cdot \mathrm{m}^{-2}$

FEV1 \% pred

FEV $1 /$ FVC \%

TLC $\%$ pred

RV/TLC \%

Room air $\mathrm{Pa}, \mathrm{O}_{2} \mathrm{kPa}$

Room air $\mathrm{Pa}_{\mathrm{a}} \mathrm{CO}_{2} \mathrm{kPa}$

Room air $\mathrm{pH}$

AHI events $\cdot h$ sleep ${ }^{-1}$

Arousal index arousals $\cdot h$ sleep $^{-1}$

Sleep efficiency

54

$68.4 \pm 8.0$

$25.3 \pm 5.5$

$24.8 \pm 8.1$

$33.1 \pm 10.0$

$116.5 \pm 23.5$

$66.9 \pm 8.2$

$6.98 \pm 2.57$

$7.26 \pm 1.06$

$7.40 \pm 0.03$

$4.9 \pm 5.1$

$16.4 \pm 8.7$

$57.4 \pm 16.0$

Data are presented as mean \pm SD unless otherwise stated. BMI: body mass index; FEV1: forced expiratory volume in one second; \% pred: $\%$ predicted; FVC: forced vital capacity; TLC: total lung capacity; RV: residual volume; $\mathrm{Pa}, \mathrm{O}_{2}$ : arterial oxygen tension; $\mathrm{Pa}, \mathrm{CO}_{2}$ : arterial carbon dioxide tension; AHI: apnoea/hypopnoea index; Sleep efficiency: (total sleep time/time available for sleep) $\times 100$.

drift in the sensor across the night was $0.21 \pm 0.65 \mathrm{kPa}(1.6 \pm$ $4.9 \mathrm{mmHg}$ ). Figure 4 is a frequency histogram of the $20 \%$ incr values. Of these 54 subjects, 23 or $43 \%$ were found to have $\mathrm{SH}$ according to the authors' a priori definition.

Tables 2 and 3 give univariate correlation coefficients between measures of $\mathrm{SH}$ and putative associated factors. Multiple linear-regression analysis produced the following equations:

$$
\begin{aligned}
& 20 \% \text { incr }=0.40 \mathrm{~Pa}_{\mathrm{a}, \mathrm{CO}_{2}}+0.34 \mathrm{BMI} \\
& +0.29 \% \mathrm{REM}-25.4\left(\mathrm{R}^{2}=0.35\right) \\
& \text { Maxincr }=0.52 P_{\mathrm{a}, \mathrm{CO}_{2}}+0.54 \mathrm{BMI} \\
& +0.39 \% \text { REM }-32.9\left(\mathrm{R}^{2}=0.48\right) \\
& \triangle \mathrm{NREM}-\mathrm{REM}=0.13 \mathrm{REM} \text { flow } \\
& +0.0028 \% \mathrm{SWS}+0.63\left(\mathrm{R}^{2}=0.19\right)
\end{aligned}
$$

where SWS is slow-wave sleep.

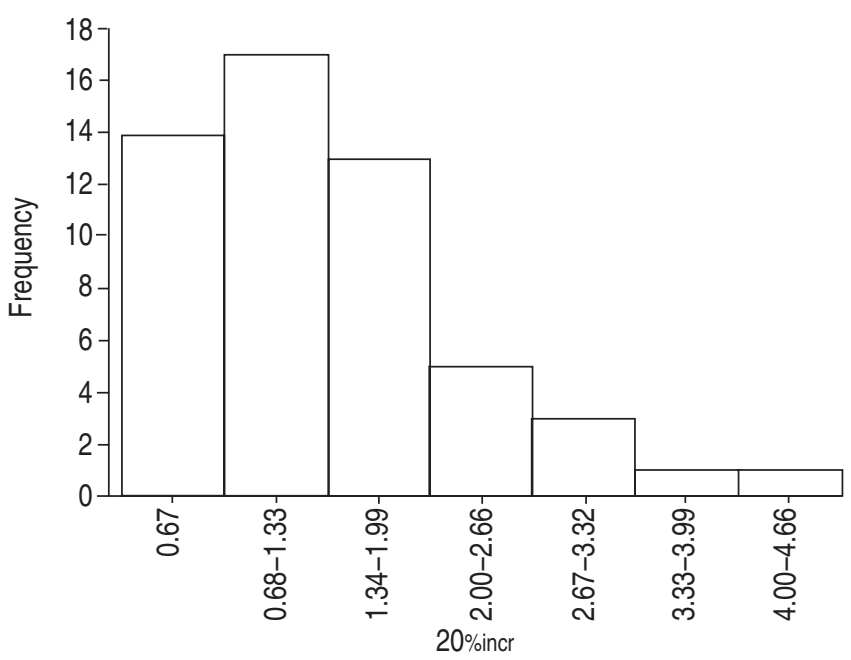

Fig. 4. - Histogram of the range of severity of sleep hypoventilation $(n=54)$. 20\%incr: increment in transcutaneous carbon dioxide tension above supine waking baseline, above which $20 \%$ of total sleep time was spent. Subjects with $20 \%$ incr $>1.33 \mathrm{kPa}(10 \mathrm{mmHg})$ were considered to demonstrate sleep hypoventilation (23 subjects).
Morning ABG samples were taken $33.5 \pm 30$ min after final wakening. Table 4 gives mean values for evening and morning $P \mathrm{a}, \mathrm{CO}_{2}, \mathrm{pH}$ and $\mathrm{H}^{+}$concentration. $P \mathrm{a}, \mathrm{CO}_{2}$ rose by $0.70 \pm 0.65 \mathrm{kPa}$

Table 2. - Univariate correlation coefficients for measures of overnight sleep hypoventilation

\begin{tabular}{lcr}
\hline & $20 \%$ incr & Maxincr \\
\hline Age & $-0.19(0.17)$ & $-0.05(0.72)$ \\
Female $^{\#}$ & $-0.15(0.27)$ & $-0.10(0.50)$ \\
BMI & $0.27(0.05)$ & $0.37(0.01)$ \\
FEV1\% pred & $0.19(0.17)$ & $0.19(0.19)$ \\
FVC \% pred & $0.05(0.72)$ & $-0.06(0.71)$ \\
FEV1/FVC & $0.10(0.46)$ & $0.25(0.08)$ \\
$P_{2}, O_{2}$ & $-0.18(0.24)$ & $-0.18(0.26)$ \\
$P a, C_{2}$ & $0.39(0.009)$ & $0.42(0.007)$ \\
Life alcohol $_{\text {Current alcohol }}^{\#}$ & $-0.29(0.06)$ & $-0.11(0.52)$ \\
AHI & $-0.31(0.04)$ & $-0.23(0.14)$ \\
\%SWS & $0.13(0.33)$ & $0.22(0.13)$ \\
\%REM & $-0.10(0.46)$ & $-0.05(0.75)$ \\
TST & $0.28(0.04)$ & $0.32(0.03)$ \\
REMflow & $0.18(0.19)$ & $0.17(0.25)$ \\
NREMflow & $0.12(0.53)$ & $0.17(0.37)$ \\
& $0.00(0.98)$ & $0.16(0.38)$ \\
\hline
\end{tabular}

Data are presented as univariate correlation coefficients (p-values). $20 \%$ incr: increment in transcutaneous carbon dioxide tension $\left(\mathrm{Pt}_{\mathrm{t}} \mathrm{CO}_{2}\right)$ from wakefulness above which $20 \%$ of total sleep time (TST) was spent; Maxincr: maximum increment in $P \mathrm{t}, \mathrm{CO}_{2}$ over wakefulness; $\mathrm{BMI}$ : body mass index; FEV1: forced expiratory volume in one second; \% pred: $\%$ predicted; FVC: forced vital capacity; $\mathrm{Pa}, \mathrm{O}_{2}$ : arterial oxygen tension; $\mathrm{Pa}_{2} \mathrm{CO}_{2}$ : arterial carbon dioxide tension; Life alcohol: lifetime alcohol consumption; Current alcohol: current alcohol consumption; AHI: apnoea/hypopnoea index; \%SWS: percentage TST in slow-wave sleep; \%REM: percentage TST in rapid-eye movement (REM) sleep; REMflow: mean score per breath for inspiratory flow limitation in REM sleep; NREMflow: mean score per breath for inspiratory flow limitation in non-REM sleep. \#: non-normally distributed variable.

Table 3.-Univariate correlation coefficients for sleep hypoventilation in rapid-eye movement (REM) sleep

$\triangle$ NREM-REM
Age

Female $^{\#}$

BMI

FEV1 \% pred $^{\#}$

FVC \% pred

FEV1/FVC

$\mathrm{Pa}, \mathrm{O}_{2}$

$\mathrm{Pa}, \mathrm{CO}_{2}$

Life alcohol ${ }^{\#}$

Current alcohol ${ }^{\#}$

$\mathrm{AHI}^{\#}$

AHI in REM sleep ${ }^{\#}$

$\%$ REM

$\%$ SWS

REMflow

NREMflow
$-0.13(0.29)$

$-0.03(0.78)$

$0.09(0.45)$

$0.04(0.75)$

$-0.29(0.02)$

$0.20(0.1)$

$-0.02(0.85)$

$0.18(0.17)$

$0.02(0.88)$

$-0.08(0.55)$

$0.25(0.04)$

$0.24(0.05)$

$-0.12(0.32)$

$0.32(0.01)$

$0.31(0.04)$

$0.05(0.71)$
Data are presented as univariate correlation coefficients (p-values). $\triangle$ NREM-REM: change in transcutaneous carbon dioxide tension on entry to REM from nonrapid-eye movement (NREM) sleep; BMI: body mass index; FEV1: forced expiratory volume in one second; $\%$ pred: \% predicted; FVC: forced vital capacity; $\mathrm{Pa}, \mathrm{O}_{2}$ : arterial oxygen tension; $\mathrm{Pa}_{\mathrm{a}} \mathrm{CO}_{2}$ : arterial carbon dioxide tension; Life alcohol: lifetime alcohol consumption; Current alcohol: current alcohol consumption; AHI: apnoea/hypopnoea index; \%REM: percentage total sleep time (TST) in REM sleep; \%SWS: percentage TST in slow-wave sleep; REMflow: mean score per breath for inspiratory flow limitation in REM sleep; NREMflow: mean score per breath for inspiratory flow limitation in non-REM sleep. ${ }^{\#}$ : non-normally distributed variable. 
Table 4. - Night-to-morning changes in blood gas parameters

\begin{tabular}{lllr}
\hline & Night & Morning & Change \\
\hline $\mathrm{Pa}_{\mathrm{a}} \mathrm{CO}_{2} \mathrm{kPa}$ & $7.86 \pm 1.37$ & $8.57 \pm 1.65$ & $0.70 \pm 0.65^{* * *}$ \\
$\mathrm{pH}$ & $7.38 \pm 0.04$ & $7.35 \pm 0.05$ & $-0.03 \pm 0.03^{* * *}$ \\
$\mathrm{H}^{+}$concentration $\mathrm{mmol} \cdot \mathrm{L}^{-1}$ & $42.3 \pm 4.0$ & $45.1 \pm 4.9$ & $2.8 \pm 3.2^{* * *}$ \\
\hline
\end{tabular}

Data are presented as mean \pm SD. ${ }^{* * *}: \mathrm{p}<0.001$.

Table 5.-Univariate correlation coefficients for night-tomorning changes in awake arterial carbon dioxide tension $\left(\mathrm{Pa}, \mathrm{CO}_{2}\right)$

\begin{tabular}{|c|c|}
\hline & $\Delta P \mathrm{a}, \mathrm{CO}_{2}$ \\
\hline Age & $-0.35(0.003)$ \\
\hline Female $^{\#}$ & $0.28(0.02)$ \\
\hline BMI & $0.27(0.03)$ \\
\hline $20 \%$ incr & $0.78(<0.001)$ \\
\hline Maxincr & $0.69(<0.001)$ \\
\hline$\triangle$ NREM-REM & $0.28(0.04)$ \\
\hline$P \mathrm{a}, \mathrm{CO}_{2}$ & $0.42(0.002)$ \\
\hline $\mathrm{Pa}, \mathrm{O}_{2}$ & $-0.28(0.04)$ \\
\hline $\mathrm{pH}$ & $-0.25(0.07)$ \\
\hline FEV1 $\%$ pred & $-0.04(0.75)$ \\
\hline FEV1/FVC & $0.02(0.84)$ \\
\hline $\mathrm{RV}^{\mathrm{T} L C^{\#}}$ & $-0.12(0.34)$ \\
\hline $\mathrm{AHI}^{\#}$ & $0.02(0.89)$ \\
\hline$\%$ REM & $0.16(0.20)$ \\
\hline REMflow & $0.03(0.83)$ \\
\hline NREMflow & $0.06(0.70)$ \\
\hline Current alcohol $^{\#}$ & $-0.27(0.04)$ \\
\hline Life alcohol ${ }^{\#}$ & $-0.34(0.01)$ \\
\hline
\end{tabular}

Data are presented as univariate correlation coefficients (p-values). BMI: body mass index; $20 \%$ incr: increment in transcutaneous carbon dioxide tension $\left(\mathrm{Pt}_{1}, \mathrm{CO}_{2}\right)$ from wakefulness above which $20 \%$ of total sleep time (TST) was spent; Maxincr: maximum increment in $\mathrm{Pt}_{\mathrm{t}} \mathrm{CO}_{2}$ over wakefulness; $\triangle$ NREM-REM: change in transcutaneous carbon dioxide tension on entry to rapid-eye movement (REM) sleep from nonrapid-eye movement (NREM) sleep; $\mathrm{Pa}, \mathrm{O}_{2}$ : arterial oxygen tension; FEV1: forced expiratory volume in one second; \% pred: \% predicted; FVC: forced vital capacity; RV: residual volume; TLC: total lung capacity; AHI: apnoea/hypopnoea index; \%REM: percentage TST in REM sleep; REMflow: mean score per breath for inspiratory flow limitation in REM sleep; NREMflow: mean score per breath for inspiratory flow limitation in non-REM sleep; Current alcohol: current alcohol consumption; Life alcohol: lifetime alcohol consumption. "\#: nonnormally distributed variable.

(5.29 $44.92 \mathrm{mmHg})$ across the night $(\mathrm{p}<0.001)$. Night-to-morning $\Delta \mathrm{Pa}, \mathrm{CO}_{2}$ correlated with all measures of $\mathrm{SH}$ (table 5).

Multiple regression analysis produced the following equation:

$$
\Delta P \mathrm{a}, \mathrm{CO}_{2}=0.5320 \% \text { incr }-0.13 \mathrm{age}+8.8\left(\mathrm{R}^{2}=0.66\right)
$$

\section{Discussion}

This study has shown that $\mathrm{SH}$ is common in hypercapnic COPD, occurring in $43 \%$ of the population. Severity of $\mathrm{SH}$ correlated with daytime $\mathrm{Pa}, \mathrm{CO}_{2}$ and with $\mathrm{BMI}$, and during REM with severity of inspiratory flow limitation and with AHI. In contrast to earlier reports in normal subjects [18, 19], the authors found a significant increase in waking carbon dioxide tension $\left(\mathrm{PCO}_{2}\right)$ between night and morning in these hypercapnic COPD patients. The night-to-morning rise in $\mathrm{Pa}, \mathrm{CO}_{2}$ was highly correlated with severity of $\mathrm{SH}$. This is the first study to document the prevalence of $\mathrm{SH}$ in hypercapnic COPD. A number of studies have examined the prevalence of REM-related oxygen desaturation in sleep in COPD $[8,20$,
21]. However these desaturations may be partially due to $V^{\prime} / Q^{\prime}$ disturbance $[7,9]$. One previous study measured $P \mathrm{t}, \mathrm{CO}_{2}$ during sleep in 23 COPD patients and 33 normal controls [22]. Mean maximal increase in $\mathrm{Pt}, \mathrm{CO}_{2}$ was $0.80 \mathrm{kPa}(6 \mathrm{mmHg})$ in the COPD patients and was not different to the controls. These results differ from those in the current study, probably because few of the patients in the study by MIDGREN and HANSSON [22] were hypercapnic $\left(\mathrm{Pa}_{1} \mathrm{CO}_{2} \quad 5.59 \pm 0.80 \mathrm{kPa}\right.$ $(42 \pm 6 \mathrm{mmHg}))$. In the present study, there was a strong correlation in the subjects between daytime $\mathrm{Pa}, \mathrm{CO}_{2}$ and severity of $\mathrm{SH}$. Previously, hypercapnia has been shown to be a risk factor for REM-related desaturation in COPD $[8,21,23]$.

OSAH appears be an important cause of hypercapnia in some patient groups [10, 14, 24]. Continuous positive airways pressure has been shown to restore eucapnia and increase ventilatory response to $\mathrm{CO}_{2}$ in morbidly obese hypercapnic patients with OSAH [24]. Hypercapnia that appears disproportionate to level of lung function impairment has been associated with the presence of obstructive sleep apnoea (OSA) in COPD patients [10]. CHAN et al. [14] showed that hypercapnic COPD patients had many more sleep-disordered breathing events, had higher BMIs and smaller upper airway cross-sectional areas than eucapnic controls matched for lung function.

In the current study, the hypothesis that lesser degrees of upper airways obstruction, other than OSAH, could contribute to sleep hypoventilation in severe COPD was addressed. Even after exclusion of patients with OSAH, severity of inspiratory flow limitation in REM, and AHI in both REM and NREM sleep were found to be predictive of REM-related hypoventilation. BMI was significantly correlated with $\mathrm{SH}$ across the whole night.

A surprising finding was an inverse correlation with alcohol consumption. This negative correlation seems counterintuitive given what is known about the acute effects of alcohol in sleep, especially in males $[25,26]$. These findings could not be explained by a reduction in REM sleep due to chronic alcohol abuse. It is possible that heavy drinkers who were susceptible to the effects of alcohol on sleep-disordered breathing were excluded from the study due to a diagnosis of OSAH, leaving a "survivor population" who either drank minimal alcohol or were not susceptible to sleep-disordered breathing. Ultimately, the authors do not have a definite explanation for this finding, which may be due to chance.

Another interesting result was the finding that \%SWS was an independent predictor of NREM-to-REM change in $P \mathrm{t}, \mathrm{CO}_{2}$. This may also be a chance finding but may relate to the fact that the upper airway is more stable in SWS than in lighter NREM stages; in REM it is at its most vulnerable to collapse [27]. Therefore the transition from SWS to REM would be more likely to produce the greatest change in ventilation.

Daytime $\mathrm{Pa}, \mathrm{CO}_{2}$ was the factor most strongly associated with both $20 \%$ incr and maxincr. This is consistent with a number of studies that have shown daytime hypercapnia and awake ventilatory response to $\mathrm{CO}_{2}$ correlated with propensity to REM-related desaturation in COPD [8, 20, 23]. Correlations cannot prove causation, and even if the factors are causally related, they do not establish direction of causation. It is possible that worsening daytime hypercapnia is the result, not the cause of SH. The largest study of predictors of hypercapnia in COPD included BMI in the final regression equation for $\mathrm{CO}_{2}$ [28]. While obesity may influence daytime $\mathrm{Pa}, \mathrm{CO}_{2}$ via mass loading of the chest wall, both in wakefulness and sleep, it may also increase upper airway resistance in sleep, worsening SH and blunting chemosensitivity.

The authors found that $P \mathrm{a}, \mathrm{CO}_{2}$ remained elevated over evening levels $33.5 \pm 30 \mathrm{~min}$ after final wakening. They believe 
this is the first report of such a change in the literature. This contrasts with normal subjects who show no difference in $P \mathrm{CO}_{2}$ before and after sleep [18, 19]. $\triangle P a, \mathrm{CO}_{2}$ was highly correlated with severity of SH (table 3 ) and the combination of $20 \%$ incr and age explained $66 \%$ of the variance. The authors believe this provides supporting evidence for the theory that nocturnal hypoventilation can influence daytime $\mathrm{Pa}, \mathrm{CO}_{2}$ in severe COPD.

It has been proposed that SH contributes to development of chronic hypercapnia in COPD through the mechanism of gradual renal $\mathrm{HCO}_{3}^{-}$retention. Night-to-morning changes in $\mathrm{HCO}_{3}{ }^{-}$observed in the present population were compared with the change predicted for acute on chronic hypercapnia in published equations [29], but the authors were unable to demonstrate any renal $\mathrm{HCO}_{3}{ }^{-}$retention across the night due to SH. Therefore, if little or no renal compensation occurred, why did these patients not return to their presleep ventilatory status on wakening? There are a number of possible explanations for this. First, renal $\mathrm{HCO}_{3}{ }^{-}$retention may have occurred in the subjects but was too small to be detected because of the wide confidence intervals of the predicted response [29]. Second, compensation may have occurred in the cerebrospinal fluid overnight. With the fall in $\mathrm{Pa}, \mathrm{CO}_{2}$ on awakening, the cerebrospinal fluid would become relatively alkalotic, increasing $\mathrm{pH}$ in the environment of the medullary chemoreceptors and so reducing respiratory drive. A third possible explanation for the results is that acute hypercapnia has significant negative effects on the ability of the respiratory muscles to generate force and predisposes them to fatigue [30]. Therefore, it may be that despite similar respiratory centre output, the mechanical response of the muscles is temporarily impaired in the first few hours after waking in patients with significant SH. Finally, there may be a contribution from the normal circadian rhythms of hypercapnic ventilatory response and end-tidal $\mathrm{CO}_{2}[31]$.

\section{Methodological considerations}

Study population. As with all clinical trials the study population consisted only of those subjects who were both referred for assessment and consented to be enrolled in the AVCAL trial. This process always includes some referral bias. However, the authors attempted to avoid studying a population only referred for sleep assessment as much as possible.

Patients who were morbidly obese (BMI $\geqslant 40$ ) were excluded and the mean BMI of the study population was $25.7 \pm 5.7 \mathrm{~kg} \cdot \mathrm{m}^{-2}$. In addition patients with concomitant OSA were excluded. Mean AHI of the study population was 4.7 \pm 5.0 . The lowest quartile of median AHI scores in the 5,046 participants in the Sleep Heart Health Study [16] had an AHI up to 18.3 when no desaturation criterion was included in the definition of hypopnoea, compared with the lowest quartile of up to AHI 3.7, when using a definition also requiring 3\% desaturation. The authors believe therefore that using an AHI cut-off of 20 to exclude patients with OSA was justified.

From 80 patients studied, 26 were excluded for technical reasons. However, there was no difference in any of the baseline characteristics recorded between the excluded subjects and those whose data was retained. The authors believe that the group studied was truly representative of the general hypercapnic COPD population.

Use of supplemental oxygen. Supplemental oxygen may worsen hypercapnia during sleep in COPD [32]. Therefore, it is possible that $\mathrm{SH}$ would have been less severe if these patients had been studied without oxygen. However all subjects were studied on their usual prescribed oxygen flow. Therefore, the authors believe the data more truly represents $\mathrm{SH}$ in the clinical situation. In addition, they felt that if severe desaturation was seen, or if the patient became very dyspnoeic during the night it would have been ethically unacceptable to withhold oxygen from patients for whom it was part of their usual therapy. If oxygen were recommenced part way through the study this would have invalidated $\mathrm{Pt}, \mathrm{CO}_{2}$ and $\mathrm{Pa}, \mathrm{CO}_{2}$ measurements, as any changes could have been due to reintroduction of oxygen.

Transcutaneous carbon dioxide tension measurement. SH has been defined as an abnormal increase in $\mathrm{Pa}, \mathrm{CO}_{2}$ during sleep [4]. Diagnostic criteria proposed by this task force required an increase in $\mathrm{Pa}, \mathrm{CO}_{2}>1.33 \mathrm{kPa}(10 \mathrm{mmHg})$ from awake supine values during sleep or oxygen desaturation during sleep not explained by apnoea or hypopnoea events.

For the reasons elaborated above, the authors felt they could not withhold oxygen from these patients during their polysomnographs. Furthermore, comparison of severity of hypoventilation using oxygen saturation is difficult when patients begin at different points on the oxyhaemoglobin desaturation curve. Finally, desaturation is a nonspecific finding, which may also be caused by change in lung or closing volume with deterioration in $V^{\prime} / Q^{\prime}$ inequality $[4,7]$. Therefore, oxygen saturation was not used as an index of $\mathrm{SH}$.

Insertion of an indwelling arterial line to measure $\mathrm{Pa}, \mathrm{CO}_{2}$ could not be justified in this clinical trial and was likely to deter patients from enrolling. It is accepted that $P \mathrm{t}, \mathrm{CO}_{2}$ is an imperfect measure of $\mathrm{Pa}, \mathrm{CO}_{2}$. There are many reasons for the differences in the two values when measured simultaneously [33] and commercial $\mathrm{Pt}, \mathrm{CO}_{2}$ monitors incorporate software to correct for some of these factors. A number of studies in adults have found high correlations with simultaneous $\mathrm{Pa}, \mathrm{CO}_{2}$ [33-35]. Control of sleep-related increases in $\mathrm{Pt}, \mathrm{CO}_{2}$ has also been found to be a predictor of improvement in daytime $\mathrm{Pa}, \mathrm{CO}_{2}$ with noninvasive positive-pressure ventilation in COPD [6]. Nevertheless, two studies in the setting of $\mathrm{SH}$ have found large discrepancies between $P \mathrm{t}, \mathrm{CO}_{2}$ and simultaneously measured $\mathrm{Pa}, \mathrm{CO}_{2}[36,37]$. Neither of these studies used the approach of in vivo calibration of the device, though the study of ROSNER et al. [37] suggested accuracy and precision would be improved if this were performed. After in vivo calibration the question becomes whether $\mathrm{Pt}, \mathrm{CO}_{2}$ accurately reflects change in $P \mathrm{a}, \mathrm{CO}_{2}$. Some studies have found a systematic increase in $\mathrm{Pt}, \mathrm{CO}_{2}-\mathrm{Pa}, \mathrm{CO}_{2}$ as $\mathrm{Pa}, \mathrm{CO}_{2}$ increases [34, 37] although others have found no such bias $[35,36]$. There was no evidence of a systematic overestimation of $\Delta P \mathrm{a}, \mathrm{CO}_{2}$ by $P \mathrm{t}, \mathrm{CO}_{2}$ as $\Delta \mathrm{Pa}, \mathrm{CO}_{2}$ increased in these data (fig. 3). The authors therefore concluded that changes in $P \mathrm{t}, \mathrm{CO}_{2}-\mathrm{Pa}, \mathrm{CO}_{2}$ across the night were due to sensor drift. After excluding from analysis subjects in whom drift was $>1.33 \mathrm{kPa}(10 \mathrm{mmHg})$, the authors corrected for drift using the morning $\mathrm{Pa}, \mathrm{CO}_{2}$ sample. The mean correction introduced was $0.21 \pm 0.65 \mathrm{kPa}(1.6 \pm 4.9 \mathrm{mmHg})$.

Using these methods, $\mathrm{SH}$, as measured by $\mathrm{Pt}_{\mathrm{t}} \mathrm{CO}_{2}$ was highly correlated with night-to-morning change in $\mathrm{Pa}_{2} \mathrm{CO}_{2}$. Thus, while the authors cannot be certain of the precision of the $P \mathrm{t}, \mathrm{CO}_{2}$ measurements, they believe they are likely to accurately represent trends in $\mathrm{Pa}, \mathrm{CO}_{2}$ across the night.

Definition of sleep hypoventilation. There is no universally accepted definition of $\mathrm{SH}$. The recent consensus conference [4] chose a threshold value of an increase in $\mathrm{Pa}, \mathrm{CO}_{2}>1.33 \mathrm{kPa}$ $(10 \mathrm{mmHg})$ during sleep, without specifying a duration for this increase. The authors therefore chose a threshold increase of $1.33 \mathrm{kPa}(10 \mathrm{mmHg})$ in $\mathrm{Pt}, \mathrm{CO}_{2}$. It was felt that $20 \%$ of TST constituted a significant portion of the night spent with 
abnormally elevated $\mathrm{Pt}, \mathrm{CO}_{2}$ levels. However, it is clear that the prevalence of $\mathrm{SH}$ will vary depending on the definition used. Figure 4 illustrates how prevalence changes depending on the increment in $\mathrm{Pt}, \mathrm{CO}_{2}$, which is defined as significant. Likewise, if $\mathrm{SH}$ is defined as $>10 \%$ of TST spent at $>1.33 \mathrm{kPa}(10 \mathrm{mmHg})$ above baseline waking levels, the prevalence in this population would be $48 \%$, if $>40 \%$ of TST the prevalence would be $31 \%$.

To conclude, the authors have found a high prevalence of sleep hypoventilation in a large hypercapnic chronic obstructive pulmonary disease population. Sleep hypoventilation was primarily related to baseline arterial carbon dioxide tension, body mass index and, in rapid-eye movement sleep to increased upper airway resistance. These patients often have increases in arterial carbon dioxide tension between night and morning, which are strongly related to the severity of sleep hypoventilation. Further studies are needed to investigate the long-term influence of repetitive increases in carbon dioxide due to sleep hypoventilation on respiratory drive and daytime blood gases in these patients.

The complete list of AVCAL investigators. Adelaide: R.D. McEvoy, F.J. O'Donoghue, P.G. Catcheside, L.S. Rowland, R. Antic, H.W. Greville, R.E. Ruffin, A.M. Southcott. Sydney: R.R. Grunstein, D.J. Barnes, I.H.Young, E.E. Ellis, E.R. Collins. Melbourne: R.J. Pierce, K. Detering, D.A. Campbell, L.B. Irving, C.F. McDonald, C.J. Worsnop, L.M. Schachter, S.E. Rochford.

\section{References}

1. Barnes PJ. Chronic obstructive pulmonary disease. $N$ Engl $J$ Med 2000; 343: 269-280.

2. Cooper CB, Waterhouse J, Howard P. Twelve year clinical study of patients with hypoxic cor pulmonale given long term domiciliary oxygen therapy. Thorax 1987; 42: 105110 .

3. Hubmayr RD, Sieck GC. Causes of respiratory failure. In: Dempsey JA, Pack AI, eds. Regulation of Breathing. New York, Marcel-Dekker, 1995; pp. 959-980.

4. The American Academy of Sleep Medicine Task Force. Sleep-related breathing disorders in adults: recommendations for syndrome definition and measurement techniques in clinical research. Report of American Academy of Sleep Medicine Task Force. Sleep 1999; 22: 667-689.

5. Mehta S, Hill NS. Noninvasive ventilation. Am J Respir Crit Care Med 2001; 163: 540-577.

6. Meecham Jones DJ, Paul EA, Jones PW, Wedzicha JA. Nasal pressure support ventilation plus oxygen compared with oxygen therapy alone in hypercapnic COPD. Am J Respir Crit Care Med 1995; 152: 538-544.

7. Douglas NJ. Sleep in patients with chronic obstructive pulmonary disease. Clin Chest Med 1998; 19: 115-125.

8. Bradley TD, Mateika J, Li D, Avendano M, Goldstein RS. Daytime hypercapnia in the development of nocturnal hypoxemia in COPD. Chest 1990; 97: 308-312.

9. Fletcher EC, Gray BA, Levin DC. Nonapneic mechanisms of arterial oxygen desaturation during rapid-eye-movement sleep. J Appl Physiol 1983; 54: 632-639.

10. Chaouat A, Weitzenblum E, Krieger J, Ifoundza T, Oswald M, Kessler R. Association of chronic obstructive pulmonary disease and sleep apnea syndrome. Am J Respir Crit Care Med 1995; 151: 82-86.

11. Henke KG, Dempsey JA, Kowitz JM, Skatrud JB. Effects of sleep-induced increases in upper airway resistance on ventilation. J Appl Physiol 1990; 69: 617-624.

12. Bellemare F, Grassino A. Force reserve of the diaphragm in patients with chronic obstructive pulmonary disease. $J$ Appl Physiol 1983; 55: 8-15.
13. Saunders JB, Wodak AD, Haines A, et al. Accelerated development of alcoholic cirrhosis in patients with HLA-B8. Lancet 1982; 1: 1381-1384.

14. Chan CS, Bye PT, Woolcock AJ, Sullivan CE. Eucapnia and hypercapnia in patients with chronic airflow limitation. The role of the upper airway. Am Rev Respir Dis 1990; 141: 861865.

15. Rechtschafen A, Kales A. A Manual of Standardised Terminology, Techniques and Scoring System for Sleep Stages of Human Sleep. National Institutes for Health publication number 204. Bethesda, National Institute of Neurological Disease and Blindness, 1968.

16. Redline S, Kapur VK, Sanders MH, et al. Effects of varying approaches for identifying respiratory disturbances on sleep apnea assessment. Am J Respir Crit Care Med 2000; 161: 369-374.

17. Clark SA, Wilson CR, Satoh M, Pegelow D, Dempsey JA. Assessment of inspiratory flow limitation invasively and noninvasively during sleep. Am J Respir Crit Care Med 1998; 158: 713-722.

18. Birchfield RI, Sieker HO, Heyman A. Alterations in blood gases during natural sleep and narcolepsy. Neurology 1958; 8: 107-112.

19. Douglas NJ, White DP, Pickett CK, Weil JV, Zwillich CW. Respiration during sleep in normal man. Thorax 1982; 37 : 840-844.

20. Fleetham JA, Mezon B, West P, Bradley CA, Anthonisen NR, Kryger $\mathrm{MH}$. Chemical control of ventilation and sleep arterial oxygen desaturation in patients with COPD. Am Rev Respir Dis 1980; 122: 583-589.

21. Connaughton JJ, Catterall JR, Elton RA, Stradling JR, Douglas NJ. Do sleep studies contribute to the management of patients with severe chronic obstructive pulmonary disease? Am Rev Respir Dis 1988; 138: 341-344.

22. Midgren $\mathrm{B}$, Hansson L. Changes in transcutaneous $\mathrm{pCO}_{2}$ with sleep in normal subjects and in patients with chronic respiratory diseases. Eur J Respir Dis 1987; 71: 388394.

23. Perez-Padilla R, Conway W, Roth $\mathrm{T}$, Anthonisen $\mathrm{N}$, George C, Kryger M. Hypercapnia and sleep $\mathrm{O}_{2}$ desaturation in chronic obstructive pulmonary disease. Sleep 1987; 10: 216-223.

24. Berthon-Jones M, Sullivan CE. Time course of change in ventilatory response to $\mathrm{CO}_{2}$ with long-term CPAP therapy for obstructive sleep apnea. Am Rev Respir Dis 1987; 135: 144-147.

25. Block AJ, Hellard DW, Slayton PC. Effect of alcohol ingestion on breathing and oxygenation during sleep. Analysis of the influence of age and sex. Am J Med 1986; 80: 595-600.

26. Dawson A, Bigby BG, Poceta JS, Mitler MM. Effect of bedtime alcohol on inspiratory resistance and respiratory drive in snoring and nonsnoring men. Alcohol Clin Exp Res 1997; 21: 183-190.

27. Issa FG, Sullivan CE. Upper airway closing pressures in snorers. J Appl Physiol 1984; 57: 528-535.

28. Begin P, Grassino A. Inspiratory muscle dysfunction and chronic hypercapnia in chronic obstructive pulmonary disease. Am Rev Respir Dis 1991; 143: 905-912.

29. Ingram RH Jr, Miller RB, Tate LA. Acid-base response to acute carbon dioxide changes in chronic obstructive pulmonary disease. Am Rev Respir Dis 1973; 108: 225-231.

30. Juan G, Calverley P, Talamo C, Schnader J, Roussos C. Effect of carbon dioxide on diaphragmatic function in human beings. $N$ Engl J Med 1984; 310: 874-879.

31. Spengler CM, Czeisler CA, Shea SA. An endogenous circadian rhythm of respiratory control in humans. J Physiol 2000; 526: 683-694.

32. Goldstein RS, Ramcharan V, Bowes G, McNicholas WT, Bradley D, Phillipson EA. Effect of supplemental nocturnal oxygen on gas exchange in patients with severe obstructive lung disease. $N$ Engl J Med 1984; 310: 425-429. 
33. Clark JS, Votteri B, Ariagno RL, et al. Noninvasive assessment of blood gases. Am Rev Respir Dis 1992; 145: 220-232.

34. Janssens JP, Howarth-Frey C, Chevrolet JC, Abajo B, Rochat $\mathrm{T}$. Transcutaneous $\mathrm{pCO}_{2}$ to monitor noninvasive mechanical ventilation in adults: assessment of a new transcutaneous $\mathrm{pCO}_{2}$ device. Chest 1998; 113: 768-773.

35. Sridhar MK, Carter R, Moran F, Banham SW. Use of a combined oxygen and carbon dioxide transcutaneous electrode in the estimation of gas exchange during exercise. Thorax 1993; 48: 643-647.

36. Sanders MH, Kern NB, Costantino JP, et al. Accuracy of end-tidal and transcutaneous $\mathrm{pCO}_{2}$ monitoring during sleep. Chest 1994; 106: 472-483.

37. Rosner V, Hannhart B, Chabot F, Polu JM. Validity of transcutaneous oxygen/carbon dioxide pressure measurement in the monitoring of mechanical ventilation in stable chronic respiratory failure. Eur Respir J 1999; 13: 1044-1047. 